\title{
TAXONOMIC AND BIOMORPHOLOGICAL STRUCTURE OF MOUNTAIN KUZNETSOV VASCULAR PLANTS FLORA (SAMARA REGION, VOLZHSKY DISTRICT)
}

(C) 2018

\author{
Makarova Yulia Vladimirovna, candidate of biological sciences, \\ senior lecturer of Ecology, Botany and Nature Protection Department \\ Samara National Research University (Samara, Russian Federation) \\ Golovlyov Aleksey Alekseevich, doctor of geographical sciences, professor of World Economy Department \\ Samara State University of Economics (Samara, Russian Federation) \\ Prokhorova Nataliya Vladimirovna, doctor of biological sciences, \\ professor of Ecology, Botany and Nature Protection Department \\ Samara National Research University (Samara, Russian Federation)
}

Abstract. The presence of 267 vascular plants species from 190 genera, 63 families, 26 orders, 4 classes (Equisetopsida, Polypodiopsida, Pinopsida, Angiospermae) and 3 divisions (Equisetophyta, Polypodiophyta, Spermatophyta) was established for Kuznetsov Mountain. The absolute majority of species belong to Spermatophyta (258 species, 96,7\%), Angiospermae (257 species, 96,3\%), Dicotyledones (228 species, 85,4\%). Vascular spore plants are represented by 9 species belonging to 6 genera (Equisetum, Matteuccia, Athyrium, Cystopteris, Dryopteris, Pteridium), 5 families (Equisetaceae, Onocleaceae, Woodsiaceae, Dryopteridaceae, Dennstaedtiaceae), 2 classes (Equisetopsida, Polypodiopsida) and 2 divisions (Equisetophyta, Polypodiophyta). The leading families according the species diversity are Compositae (44 species, 16,5\%), Leguminosae (22 species, 8,2\%) and Rosaceae (18 species, $6,7 \%$ ). The leading families according the number of genera are Compositae ( 29 genera, 15,3\%), Rosaceae (14 genera, 7,4\%) and Labiatae (13 genera, 6,8\%). The largest number of species is concentrated in the genera Trifolium (7 species), Viola, Campanula, Galium and Carex (4 species each). According to the climamorphic system of K. Raunkiaer, hemicryptophytes predominate in the flora (148 species, 55,4\%). According to the biomorph system I.G. Serebryakov and T.I. Serebryakova - perennial polycarpic short-stemmed, long-rooted, and rod-root grasses $(47,0 \%)$ predominate. $76,8 \%$ of the species are vegetatively still and immobile.

Keywords: flora; vascular plants; taxonomic analysis; biomorphological analysis; life forms; biomorphes; climamorphes; phanerophyte; hamefit; hemicryptophyte; cryptophyte; terophyte; woody plants; half-timbered plants; herbaceous plants; vegetative mobility of biomorph; Aboriginal species; adventive species; Mountain Kuznetsov; Sokolii Mountains; Volzhsky District; Samara Region.

УДК 574.587

Статья поступила в редакцию 01.12.2017

\section{РАСПРЕДЕЛЕНИЕ МЕЙОБЕНТОСА ПО ГРАДИЕНТУ СОЛЕНОСТИ В ЭСТУАРИИ РЕКИ РАЗДОЛЬНОЙ ПРИМОРСКОГО КРАЯ}

Милованкина Александра Александровна, аспирант кафедры экологии Фадеева Наталия Петровна, доктор биологических наук, профессор кафедры экологии Дальневосточный федеральный университет (2. Владивосток, Российская Федерация)

Чертопруд Елена Сергеевна, кандидат биологических наук,

ведущий научный сотрудник кафедры гидробиологии; ведущий инженер лаборатории синэкологии Московский государственный университет имени М.В. Ломоносова (г. Москва, Российская Федераџия); Институт проблем экологии и эволючии имени А.Н. Северцуова РАН (г. Москва, Российская Федерация)

Аннотация. По результатам бентосных съемок эстуария реки Раздольной (Японское море, Амурский залив) прослежено распределение мейобентоса по градиенту солености. Плотность мейобентоса в эстуарии реки Раздольной увеличивалась с ростом показателей солености. Мейобентос представлен 8 таксономическими группами (Nematoda, Copepoda, Ostracoda, Oligochaeta, Mollusca, Amphipoda, Polychaeta и Chironomidae) при доминировании нематод. Большая часть мейобентосных видов представлена морскими эвригалинными видами, встречающимися на всем протяжении эстуария. В мейобентосе в олигогалинной зоне доминируют широко распространенные в эстуариях Дальнего Востока России пресноводные виды Dorylaimus chassanicus, Hofmaenneria gratiosa, Theristus brevisetosus и нематоды рода Paradontophora; в мезогалинной зоне Monhystrella sp., Oncholaimium japonicum, Anoplostoma cuticularia, Daptonema inversum, а также гарпактикоиды Remanea naksanensis, Onychocamptus mohammed, Huntemannia biarticulatus, Halectinosoma sp. На всем протяжении эстуария реки Раздольной состав нематод изменяется по зонам: для пресной воды и олигогалинной зон характерно доминирование нематод рода Paradontophora, а также наличие пресноводных видов (Dorylaimus chassanicus, Hofmaenneria gratiosa, Theristus brevisetosus); для мезогалинной зоны - доминирование Monhystrella sp. и снижение числа пресноводных видов; для эугалинной зоны - доминирование Paracanthonchus macrodon, Oncholaimium paraolium, Sabatieria finitima, Dorylaimopsis peculiaris и S. palmaris. Нематоцены внутренней части эстуарной зоны не отличаются специфическим набором видов и состоят из видов, характерных для сообщества нематод как опресненной, так и морской зон. 
Милованкина А.А., Фадеева Н.П., Чертопруд Е.С. 03.02.00 - общая биология Распределение мейобентоса по градиенту солености в эстуарии реки Раздольной..

Ключевые слова: мейобентос; свободноживущие нематоды; нематоцены; гарпактикоидные копеподы; таксономический состав; биоразнообразие; эстуарий; градиент солености; олигогалинная зона; мезогалинная зона; пресноводная зона; эвригалинность; виды пресноводного генезиса; виды морского генезиса; численность; биомасса; распределение; Приморский край; река Раздольная; Амурский залив; Японское море.

\section{Введение}

Эстуарии, расположенные в зоне контакта морских и пресных вод, характеризуются выраженным градиентом солености. Соленостный режим является одним из ключевых факторов, определяющих все важнейшие характеристики эстуарных сообществ [13]. Эстуарная зона реки Раздольной является районом наиболее активной хозяйственной деятельности в северо-западной части побережья Японского моря (залив Петра Великого) и подвергается антропогенному воздействию [4].

Эстуарий реки Раздольная долинного типа состоит из внутренней и внешней частей, граница между которыми проходит по гребню устьевого бара, пространственно совпадающего с траверзом входных мысов из Амурского залива в преддельтовый Тавричанский лиман. Соленость в придонном слое изменяется от $(0,26-1,25 \%)$ до $20 \%$ в наиболее глубоких местах. В Тавричанском лимане соленость достигает $26,3 \%$.

В настоящее время в литературе имеются весьма скудные и противоречивые данные о характере структурных изменений мейобентоса (организмов размером <1 мм) вдоль средовых градиентов в эстуарии: показано как отсутствие каких-либо направленных изменений, связанных с соленостью [5; 6], так и увеличение или уменьшение плотности и биомассы с уменьшением солености [7-9].
Данные по биоразнообразию мейобентоса всего эстуария (или его частей) реки Раздольной представлены в публикациях, посвященных отдельным его группам: остракодам [8], свободноживущим нематодам $[9 ; 10]$ и основаны на разных по объему материалах. До сих пор нет сведений об особенностях пространственного распределения мейобентоса во внутренней части эстуария реки Раздольной и в пресноводных участках, примыкающих к нему.

В данной работе мы анализируем изменение характеристик мейобентоса, а также структурных изменений его основных групп по градиенту солености в эстуарии реки Раздольная (Амурский залив Японского моря) по собственным и литературным данным.

\section{Материалы и методика исследований}

Исследования были проведены в 2013-2014 гг. в летне-осенний период (при $\mathrm{t}$ от $20^{\circ} \mathrm{C}$ до $20,15^{\circ} \mathrm{C}$ ) во внутреннем эстуарии реки Раздольной (Амурский залив Японского моря) в диапазоне глубин от 0,5 м до 2,1 м на 20 станциях, которые располагались на расстоянии несколько сотен метров друг от друга (рис. 1). Пробы для изучения гидрохимических и седиментационных характеристик были взяты одновременно с пробами грунта, а данные опубликованы [11]. Соленость в придонном слое изменялась от пресных $(0,26-1,25 \%)$ до 5-8\%о в Тавричанском лимане.

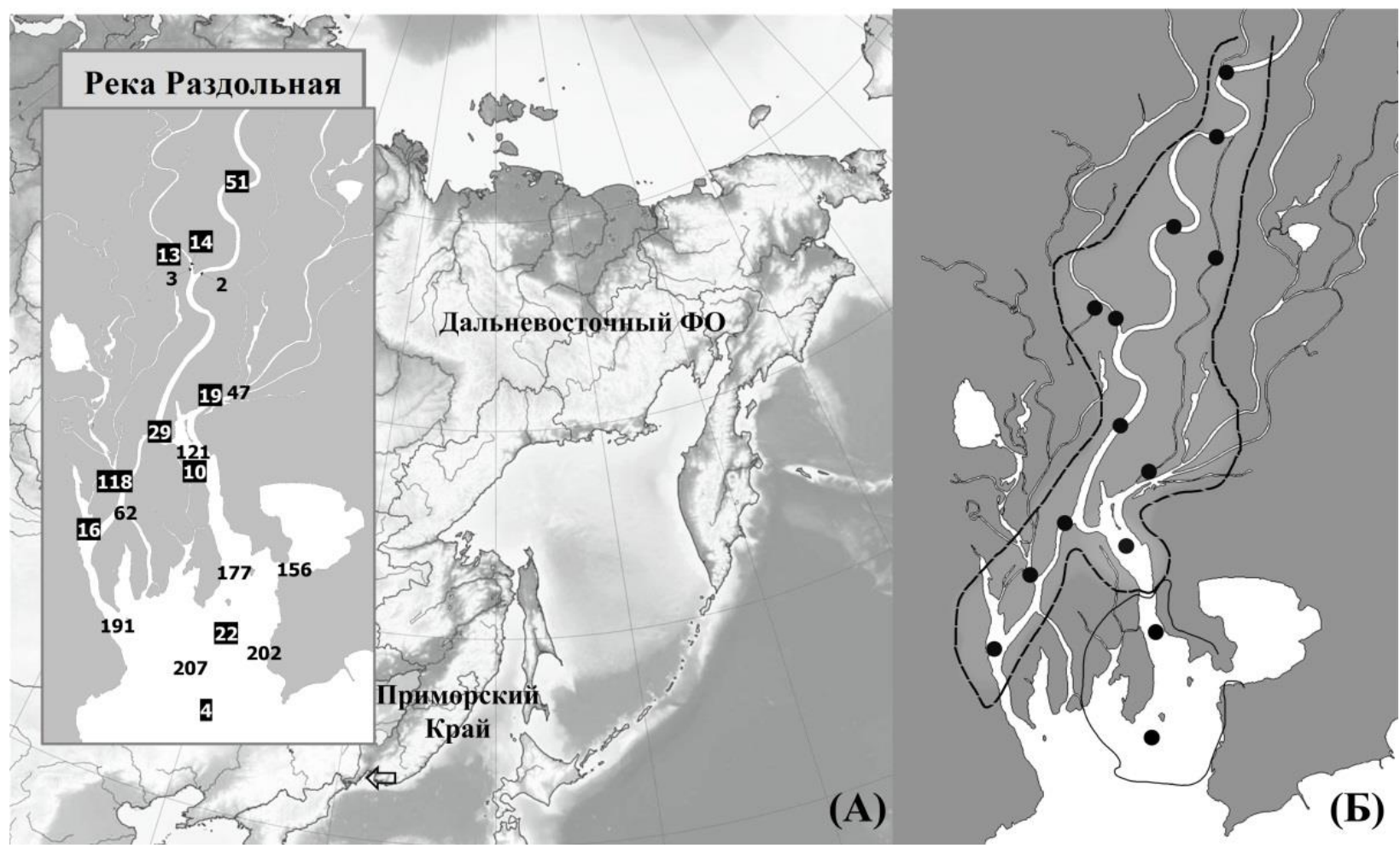

Рисунок 1 - Карта-схема района исследований. Цифрами отмечены точки отбора проб донных осадков. В черных квадратах станции за 2013 год, без фона за 2014 год $(A)$. Зона внутреннего эстуария р. Раздольной выделена пунктиром, часть зоны внутреннего эстуария - сплошной линией (Б) [11]

Пробы собирали трубчатым пробоотборником (внутренний диаметр 4,6 см, глубина 4 см, площадь вырезания грунта $20 \mathrm{~cm}^{2}$ ). Выделение мейобентосных организмов из грунта производили по стандартной методике с использованием сит с размером ячеи 32 мкм и фиксировали 4\% забуференным формальдегидом. 
Биомассу каждой группы мейобентоса вычисляли умножением плотности поселения на среднюю массу представителей. Сырую массу животных рассчитывали с помощью формулы: $W=V p$, где $W$ - масса, мкг, $V$ - объем организмов, нл, $V, \mathrm{nl}:$ ([D $] / 1000)$ (([S]/1000) ([S]/1000)). $D$ - длина организма; $S$ - ширина организма; $p$ - удельная масса, равная для брюхоногих и двустворчатых моллюсков $1,5 \mathrm{mг} / \mathrm{M}^{3}$, для

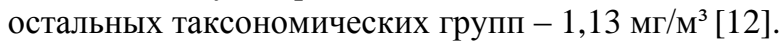

Выделение нематоценов было основано на методе непараметрического многомерного шкалирования для ординации проб, в качестве метрики использовали индекс Брея-Кертиса для трансформированных (корень квадратный) данных по относительному обилию типов сочетаний функциональных групп. Статистическую значимость группировок оценивали с помощью анализа сходства (ANOSIM) в программax Past3 и STATISTICA 10 [13]. Корреляционный анализ Спирмена и анализ сходства (ANOSIM BrayCurtis) проведены в программе StatSoft STATISTICA 10, PRIMER и Past3.

\section{Результаты исследований}

Плотность поселения мейобентосных организмов во внутренней части эстуария реки Раздольной при солености $<5 \%$ изменялась от 6 до 151 тыс. экз./ м $^{2}$ и сильно зависела от сезона (в июле $71,5 \pm 14,4$ и $16,6 \pm 2,9$ тыс. экз./ $/ \mathrm{M}^{2}$ в сентябре) (табл. 1 ).

В этой части эстуария были найдены восемь групп разного таксономического ранга: Nematoda, Copepoda, Ostracoda, Oligochaeta, Mollusca, Amphipoda, Polychaeta и Chironomidae. На всех станциях доминировали свободноживущие нематоды, вторыми были либо гарпактикоиды, либо олигохеты в зависимости от типа грунта или скорости течения.

Биомасса мейобентосных организмов характеризовалась значительными колебаниями и составляла от 2 до 1609 мкг сырой массы $/ \mathrm{M}^{2}$, тогда как биомасса нематод практически не изменялась (средняя $1,9 \pm 0,8$ мкг сырой массы $/ \mathrm{M}^{2}$ ) (табл. 1). Минимальные значения отмечались в Тавричанском лимане на псаммитах мелкозернистых и миктитах алевритовых (определялись низкой биомассой нематод), а максимальные - в пресных водах и олигогалинной части эстуария (определялись биомассой олигохет и хирономид) (рис. 2, табл. 1, 2).

Плотность поселения нематод изменялась от 4,5 тыс. экз./ $\mathrm{M}^{2}$ до 146,5 тыс. экз./ $\mathrm{M}^{2}$ при средних значениях $67,6 \pm 14,0$ в июле и $13,9 \pm 2,7$ в сентябре (табл. 1).

В результате проведенного корреляционного анализа Спирмена была выявлена слабоположительная связь между соленостью и плотностью поселения нематод и слабо отрицательные связи между соленостью и биомассой мейобентоса (коэффициент корреляции Спирмена равен $-0,2$, и $-0,4 \mathrm{p}<0,05$ соответственно) в эстуарии реки Раздольной.

Нематоды. В речных водах в области внутреннего эстуария выявлено 40 видов свободноживущих нематод, относящихся к 33 родам и 18 семействам (табл. 2). В результате кластерного анализа была построена дендрограмма сходства станций по видовой структуре нематод (индекс Брея-Кертиса по данным о численности нематод) (рис. 2). Значимость различий выделенных групп подтверждается на уровне (p-
0,076). При анализе сходства (ANOSIM, Bray-Curtis) с уровнем достоверности $\mathrm{p}-0,81$ величина различия составила 0,71. Нематоцены характеризуются низким межвидовым и межстанционным сходством (среднее около 0,2), а также относительно независимым распределением видов по эстуарию (рис. 2). Проведенная классификация показала (рис. 2), что все станции достаточно четко разделяются на 2 основные группы (I и II) по средним показателям обилия и видового богатства.

Группа станций I занимает преимущественно участок пелитов алевритовых ( $M d-0,51$ мм, $P l-$ $79,4 \%$ и и охватывает постоянно пресноводные $(<0,5 \%$ б) биотопы бассейна нижнего течения реки Раздольная (ст. 51, 14, 2, 3, 19, 29, 47) (рис. 1, 2). Среди 24 видов нематод, обнаруженных в этой зоне, лишь 5 являются пресноводными (Dorylaimus chassanicus, Hofmaenneria gratiosa, Theristus brevisetosus, а также 2 вида сем. Dorylaimidae). Основу этого нематоцена по плотности поселения составляют представители рода Parodontophora. Высокую плотность поселения имели Tripyloides sp. и Leptolaimus sp. (табл. 2).

Станции группы II расположены во внутренней части эстуария на границе речного и солоноватоводных участков в осадках с наибольшим количеством мелкоалевритовой фракции, которое уменьшается при переходе к пресноводной части $(M d-1,53$ мм, $P l$ - 40-46\%) и включают олигогалинные $(0,5-5 \%$ ) воды эстуария (ст. 118, 62, 10, 13, 16), а также лагуну Тихая (ст. 156) и Тавричанский лиман (ст. 191, 121, $22,202,177)$ с мезогалинными (5-18\%о) водами. В олигогалинной зоне (II, А) из 22 видов свободноживущих нематод встречено лишь два пресноводных вида Paraphanolaimus sp. и Dorylaimidae gen. sp. (табл. 2). Локальные сообщества, формирующиеся в этой зоне эстуария, представляют собой различные варианты комбинаций морских и солоноватоводных видов, отвечающие местным условиям (в первую очередь режиму солености), где доминируют Нуроdontolaimus ornatus и Parodontophora timmica, многочисленны Daptonema setosum и др. (табл. 2). В мезогалинной зоне (II, В) число видов возрастает до 26 , здесь обитают солоноватоводные и морские эвригалинные виды (Oncholaimium japonicum, Anoplostoma cuticularia, Daptonema inversum, предпочитающие среднюю соленость 4-8-10\%о), но выдерживающие как продолжительное ее снижение до $0 \%$, так и повышение до 15\% (в некоторые сезоны до 18-20\%). По видовой структуре это сообщество имеет эвригалинный, неспецифический характер, с преобладанием нематод среднего и мелкого размера, обычных на песчаных грунтах разной степени заиленности. Доминируют типичные интерстициальные формы, представители сем. Monhysteridae - Monhystrella sp. (табл. 2).На границе пресноводной и мористой части эстуария реки Раздольная в зоне экстремального колебания солености в летний период (ст. 4 и 22) обитают нематоды Sabatieria pulchra, способные глубоко проникать в толщу грунта и адаптироваться к восстановительным условиям.

По результатам ординации проб методом двумерного шкалирования по обилию нематод также выделяются три группы со стрессом значений 0,17 . Расположение станций отражает распределение 
Милованкина А.А., Фадеева Н.П., Чертопруд Е.С.

нематод по градиенту солености от пресных до олиго- и мезогалинных вод во внутренней части эстуария реки Раздольной (рис. 1, 2).

Плотность гарпактикоидных копепод, второй по численности группы в мейобентосе, составляет от 0,5-4 тыс. экз./ $\mathrm{M}^{2}$. В собранных пробах наиболее часто встречаются четыре солоноватоводных вида гарпактикоид: Remanea naksanensis, Onychocamptus mohammed, Huntemannia biarticulatus, Halectinosoma sp., отмеченных ранее в эстуариях Дальнего Востока России. Характерно, что типично солоноватоводные гарпактикоиды встречаются даже в пресноводной зоне эстуария. Обнаружение солоноватоводной фауны в водах с пониженной соленостью обусловлено расслоением водных масс по глубине. Солоноватая (0,5-3\%о) вода, имеющая более высокую массу по сравнению с пресной, скапливается в углублениях дна и заполняет капилляры грунта даже в пресноводной зоне эстуария. Данная гидрологическая особенность эстуарной системы дает возможность солоноватоводным видам проникнуть в условно пресноводные биотопы. Кроме гарпактикоид в мейобентосе мезогалинной зоны отмечен представитель отряда Cyclopoida Eucyclops sp.

Ocтракодbl во внутренней части эстуария имели низкую плотность поселения по сравнению с нематодами и гарпактикоидами и были встречены лишь в протоках и в лагуне Тихой (табл. 1).

\section{Обсуждение}

Наиболее изученными по составу и распределению мейобентоса и свободноживущих нематод являются европейские эстуарные экосистемы [14-16]. Из наиболее крупных эстуариев Дальнего Востока достаточно полно исследована нематофауна реки Амур [17]. Сравнение полученных результатов с литературными данными показывает, что плотность поселения мейобентоса в эстуарии сопоставима с таковым для многих приливных эстуариев Европы [2; 5; 14-18], юго-восточной Азии [19; 20], Северной Америки и Австралии [21-23], хотя и значительно ниже максимальных значений - 14 000-22 000 экз./10 см² [15-18].

Обобщение полученных результатов с данными из внешней части эстуария по результатам бентос- ных съемок, проведенных в 1990 и 2005 гг. [9; 10], позволяет представить общую картину распределения основных групп мейобентоса в эстуария реки Раздольная (Японское море, Амурский залив). Плотность поселения мейобентосных организмов во внутренней части эстуария реки Раздольной изменялась от 6 до 151 тыс. экз./м², во внешней части эстуария по раннее опубликованным данным она варьировала от 22 до 342 тыс. экз./м² [9]. Во внешней морской части эстуария (северо-западная часть Амурского залива) плотность поселения нематод достигала $341,1 \pm 92,3$ тыс. экз./м² (на глубине 14-18 м при солености 24,34\%о) [9; 10].

В общем, плотность мейобентоса в эстуарии реки Раздольной увеличивается с ростом показателей солености. В целом мейобентосные животные преобладают на илистых грунтах эстуария реки Раздольной с повышенным содержанием органических веществ. Причем в опресненном районе, где процент алевропелита выше, общая плотность организмов мейобентоса (эвмейобентоса и личинок беспозвоночных) на некоторых станциях выше.

Нематоды доминируют в морской части эстуария, составляя приблизительно $92,5 \%$ от общей плотности поселения мейобентоса. Средние значения плотности нематод $(67,6 \pm 14,0$ в июле и $13,9 \pm 2,7$ в сентябре), полученные во внутренней части эстуария, были близки к полученным нами ранее $19,5 \pm 2,9$ тыс. экз./ м $^{2}$ для морской части эстуария на глубине до 4 м в зоне опреснения в Амурском заливе [9].

Полученные данные позволяют получить обобщенное представление о таксономическом составе мейобентоса. На основе анализа собственных и литературных данных число известных к настоящему времени видов мейобентосных животных в эстуарии реки Раздольной составило 174 вида [8-10].

Можно констатировать, что в районе исследований обнаружена качественно богатая и разнообразная донная нематофауна (111 видов), что составляет почти треть от общего числа видов, ранее известных для Японского моря [24]. В наиболее изученном эстуарии реки Амур к настоящему времени зарегистрировано 233 вида нематод [17].
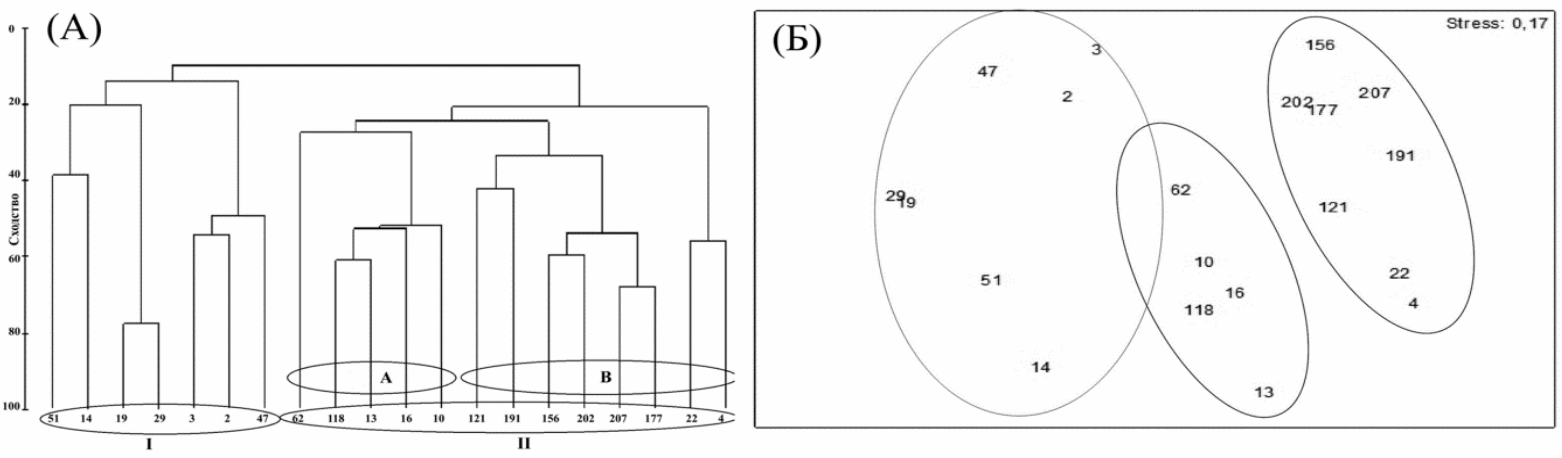

Рисунок 2 - $A$ - дендрограмма нематоценов, выделенных на основании численности нематод с помощью индекса Брея-Кертиса; Б- двумерное шкалирование изученных станций по численности нематод на основании индекса Брея-Кертиса 5

Во внутренней части эстуария нематоцены характеризуются низкой плотностью и разнообразием, во внешней - имеют максимальную численность и таксономическое разнообразие. К настоящему времени в морском внешнем эстуарии р. Раздольной (кутовая часть Амурского залива) зарегистрирован 71 вид нематод, во внутреннем солоноватом - 40 видов. С уменьшением солености воды и удаленности от моря количество видов заметно снижается. Вероятнее всего, такое распределение величин видового богатства 
Милованкина А.А., Фадеева Н.П., Чертопруд Е.С.

Распределение мейобентоса по градиенту солености в эстуарии реки Раздольной.

03.02.00 - общая биология

объясняется «парадоксом солоноватых вод» [25], в соответствии с которым зона минимума видов, определяющая относительную несмешиваемость морской и пресноводной фаун, падает на соленость 5-8\% [26]. Нематоцены внутренней части эстуарной зоны не отличаются специфическим набором видов и состоят из видов, характерных для сообщества нематод как опресненной, так и морской зон (табл. 2). На всем протяжении эстуария p. Раздольной состав нематод изменяется по зонам: для пресной воды и олигогалинной зон характерно доминирование нематод рода Paradontophora, а также наличие пресноводных видов (Dorylaimus chassanicus, Hofmaenneria gratiosa, Theristus brevisetosus); для мезогалинной зоны - доминирование Monhystrella sp. и снижение числа пресноводных видов; для эугалинной зоны доминирование Paracanthonchus macrodon, Oncholaimium paraolium, Sabatieria finitima, Dorylaimopsis peculiaris и S. palmaris, развивающиеся при средней солености выше 10-12\%, но выдерживающие кратковременное понижение до 0-2\% [2].

В опресненных районах эстуария снижается число видов отряда Desmodorida, и основные изменения в структуре эстуарных нематоценов происходят в зоне наибольшего варьирования солености воды, где отмечается высокая доля представителей отряда
Monhysterida (табл. 2). Это в целом соответствует схеме большинства изученных эстуариев [2; 18].

Видовое разнообразие гарпактикоидных копепод гораздо ниже, чем нематод, и убывает с уменьшением солености воды от моря к реке. В эстуариях количество видов копепод варьирует от 5 до 8 в мезогалинных и олигогалинных таксоценах, а в морских превышает 10 [27]. Снижение солености, как правило, ограничивает базовый набор доминирующих таксонов и видовое богатство [28].

Общая картина распределения остракод была дана Е.И. Шорниковым и М.А. Зениной [8]. В бассейне нижнего течения реки Раздольная ими обнаружен 21 пресноводный вид, а в остальных частях эстуария встречены 6 солоноватоводных и 31 вид морских остракод. Виды пресноводного генезиса Fabaeformiscandona sp. и Physocypria kraepelini проникают в олигогалинные воды с соленостью до 3,49\%. В самих протоках обитают только солоноватоводные виды. В подзоне с мезогалинными водами (4-12,79\%о) обнаружено 5 солоноватоводных видов остракод. Встречены 4 вида эвригалинных остракод Spinileberis quadriaculeata, Cytheromorpha acupunctata, Bicornucythere bisanensis и Loxoconcha sp., широко распространенные в осадках Амурского залива [8].

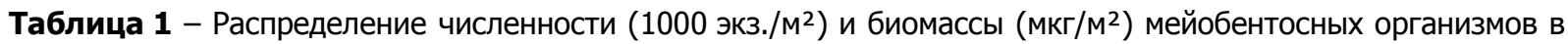
эстуарии реки Раздольной в 2013 и 2014 гг.

\begin{tabular}{|c|c|c|c|c|c|c|c|c|c|c|c|}
\hline Ст. & Сол. & Nem. & Cop. & Olig. & Pol. & Chir. & Amph. & Ostr. & Moll. & Пр. & Итого \\
\hline \multicolumn{12}{|c|}{2013} \\
\hline 4 & $<0,5 \%$ & $9,5 / 2,8$ & $0,5 / 4,3$ & - & - & - & - & - & 0,5 & - & $10,5 / 7$ \\
\hline 10 & $<0,5 \%$ & $3,5 / 1,9$ & $4 / 5,6$ & - & $0,5 / 1436$ & $0,5 / 165,4$ & - & - & - & - & $36 / 1609$ \\
\hline 13 & $<0,5 \%$ & $4,5 / 4,2$ & 0,5 & $0,5 / 32,5$ & - & - & - & - & 0,5 & - & $6 / 36,7$ \\
\hline 14 & $<0,5 \%$ & $9,5 / 2,7$ & $2 / 2,7$ & - & $0,5 / 1084$ & - & - & - & - & - & $12 / 1089$ \\
\hline 16 & $<0,5 \% 0$ & $21 / 1,9$ & $1,5 / 2$ & - & - & - & - & - & - & - & $22,5 / 3,9$ \\
\hline 19 & $<0,5 \%$ & $8,5 / 2,7$ & 0,5 & $0,5 / 59$ & - & $1,0 / 5,9$ & - & - & - & - & $10,5 / 67$ \\
\hline 22 & $<0,5 \% 0$ & $16 / 2$ & $1,5 / 7$ & $2,5 / 118$ & - & - & - & - & - & 3,0 & $23 / 127,3$ \\
\hline 29 & $4,88 \%$ o & $7,5 / 1,3$ & $3,5 / 2,7$ & - & $1 / 353,3$ & - & - & - & - & - & $12 / 361,4$ \\
\hline 51 & $0,71 \%$ o & $8,5 / 2,2$ & - & $1,0 / 5,9$ & - & $0,5 / 3,9$ & - & - & - & - & $10,2 / 12$ \\
\hline 118 & $<0,5 \%$ & $23,5 / 1,3$ & $0,5 / 3,2$ & - & - & - & $0,5 / 45,2$ & - & - & 0,5 & $24,5 / 49$ \\
\hline \multicolumn{12}{|c|}{2014} \\
\hline 2 & $<0,5 \%$ & $44 / 1,4$ & $2 / 27,3$ & $2 / 47,6$ & 1,5 & - & - & - & - & - & $49,5 / 76$ \\
\hline 3 & $<0,5 \%$ & $23,5 / 2$ & $1 / 11,8$ & $0,5 / 74,8$ & - & - & - & - & - & 0,5 & $25,5 / 89$ \\
\hline 47 & $<0,5 \%$ & $49,5 / 1$ & $2,5 / 7,6$ & $1 / 55,9$ & - & - & - & - & - & - & $53 / 64,5$ \\
\hline 62 & $<0,5 \% 0$ & $106 / 1,9$ & $2 / 5,3$ & $7 / 36$ & - & - & - & $0,5 / 9$ & - & - & $115,5 / 53$ \\
\hline 121 & $<0,5 \% 0$ & $17 / 2,1$ & - & $1 / 12,1$ & - & - & - & - & $0,5 / 67$ & - & $18,5 / 82$ \\
\hline 156 & $<0,5 \% 0$ & $77 / 2,3$ & $1 / 4,4$ & $0,5 / 20,4$ & - & - & - & $2,5 / 5$ & - & - & $81 / 32,2$ \\
\hline 177 & $<0,5 \% 0$ & $147 / 1,1$ & 1 & $3 / 56,5$ & - & - & - & - & - & 0,5 & $151 / 57,6$ \\
\hline 191 & $<0,5 \%$ & $40 / 1,6$ & - & 0,5 & - & - & - & - & - & - & $40,5 / 1,6$ \\
\hline 202 & $<0,5 \% 0$ & $47 / 1,3$ & 0,5 & $3,5 / 128$ & - & - & - & - & - & $0,5 / 2$ & $51 / 131,5$ \\
\hline 207 & $<0,5 \% 0$ & $125 / 0,8$ & $2,3 / 4,3$ & $1 / 3,4$ & - & - & - & - & - & - & $128 / 14,4$ \\
\hline
\end{tabular}

Примечание. Cm. - станция; Сол. - соленость; Nem. - Nematoda; Cop. - Copepoda; Olig. - Oligochaeta; Pol. - Polychaeta; Chir. - Chironomidae; Amph. - Amphipoda; Ostr. - Ostracoda; Moll. - Mollusca; Пр. - прочие.

\section{Выводы}

В целом найденные группы мейобентосных видов соответствуют комплексам пресноводных, солоноватоводных и морских (разной степени эвригалинности), значительно перекрываясь в своем распределении (особенно во внутреннем эстуарии). Большая часть мейобентосных видов представлена морскими эвригалинными видами, встречающимися на всем протяжении эстуария реки Раздольной. Пресноводные виды редки и встречаются спорадически во внутренней части эстуария.

Авторы выражают благодарность П.Г. Милованкину за сбор материала. 
Милованкина А.А., Фадеева Н.П., Чертопруд Е.С. 03.02.00 - общая биология Распределение мейобентоса по градиенту солености в эстуарии реки Раздольной..

Таблица 2 - Средняя плотность поселения видов свободноживущих нематод и копепод в эстуарии реки Раздольной

\begin{tabular}{|c|c|c|c|}
\hline \multirow[b]{2}{*}{ Таксон } & \multicolumn{3}{|c|}{ Плотность, тыс. экз./м² \pm стандартное отклонение } \\
\hline & $\begin{array}{c}\text { Мезогалинная } \\
\text { зона (5-8\%о) }\end{array}$ & $\begin{array}{c}\text { Олигогалинная } \\
\text { зона }(0,5-5 \%)\end{array}$ & $\begin{array}{c}\text { Пресноводная } \\
\text { зона }(<0,5 \%)\end{array}$ \\
\hline \multicolumn{4}{|l|}{ Nematoda } \\
\hline Adoncholaimus longicaudatus Paramonov, 1929 & - & $0,2 \pm 0,1$ & $0,5 \pm 0,2$ \\
\hline Anoplostoma cuticularia Belogurov, Alekseev, 1977 & $4,0 \pm 0,8$ & $0,7 \pm 0,2$ & $1,0 \pm 0,2$ \\
\hline Anticyathus plicibucca Tchesunov, Yushin, 1991 & $0,5 \pm 0,2$ & - & - \\
\hline Ascolaimus $\mathrm{sp}$. & - & $0,2 \pm 0,1$ & $3,0 \pm 1,1$ \\
\hline Axonolaimus seticaudatus Platonova, 1971 & $0,3 \pm 0,1$ & $1,5 \pm 0,7$ & $0,5 \pm 0,2$ \\
\hline Chromadorita sp. & $1,0 \pm 0,4$ & - & $0,5 \pm 0,2$ \\
\hline Cyatholaimus sp. & $3,2 \pm 0,9$ & $0,2 \pm 0,1$ & $0,5 \pm 0,2$ \\
\hline Daptonema butchlii & $0,7 \pm 0,2$ & - & - \\
\hline Daptonema inversum Alekseev, 1984 & $1,7 \pm 0,3$ & $1,7 \pm 0,5$ & $0,5 \pm 0,2$ \\
\hline Daptonema setosum Bütschli, 1874 & $0,2 \pm 0,1$ & $5,8 \pm 2,6$ & - \\
\hline Desmodora sp. & - & $1,7 \pm 0,4$ & $0,5 \pm 0,2$ \\
\hline Dichromadora sp. & $1,0 \pm 0,4$ & - & - \\
\hline Dorylaimidae gen. sp.1 & - & $0,5 \pm 0,2$ & - \\
\hline Dorylaimus chassanicus Alekseev, Naumova, 1977 & - & $0,2 \pm 0,1$ & $3,0 \pm 0,6$ \\
\hline Dorylaimidae gen. sp.2 & - & - & $1,0 \pm 0,2$ \\
\hline Elzalia sp. & $0,5 \pm 0,2$ & $0,5 \pm 0,2$ & $1,0 \pm 0,2$ \\
\hline Eumorpholaimus sp. & $3,2 \pm 0,6$ & - & - \\
\hline Hofmaenneria gratiosa Alekseev, 1983 & - & - & $1,0 \pm 0,4$ \\
\hline Hypodontolaimus ornatus Alekseev, 1970 & - & $15,3 \pm 4,2$ & $2,5 \pm 0,5$ \\
\hline Leptolaimus sp. & - & $0,2 \pm 0,1$ & $1,0 \pm 0,4$ \\
\hline Megadesmolaimus rhodinus Tchesunov, Yushin, 1991 & $0,5 \pm 0,2$ & $2 \pm 0,4$ & $0,5 \pm 0,2$ \\
\hline Microlaimus sp. & $0,5 \pm 0,1$ & - & $0,5 \pm 0,2$ \\
\hline Monhystrella sp. & $42,2 \pm 6,0$ & - & - \\
\hline Oncholaimus sp. & - & $0,3 \pm 0,2$ & - \\
\hline Viscosia stenostoma Platonova, 1971 & - & $4,0 \pm 1,0$ & $0,5 \pm 0,2$ \\
\hline Oncholaimium japonicum Belogurov, Belogurova, 1981 & $2,0 \pm 0,7$ & - & $0,5 \pm 0,2$ \\
\hline Paracanthonchus sp. & $0,5 \pm 0,2$ & - & - \\
\hline Paralongicyatholaimus sp. & $3,8 \pm 1,4$ & - & - \\
\hline Paraphanolaimus sp. & - & $0,2 \pm 0,1$ & - \\
\hline Parodonthophora timmica Pavlyuk, Belogurov, 1979 & $3,65 \pm 4,8$ & $15,3 \pm 1,6$ & $29,0 \pm 10,3$ \\
\hline Parodontophora marisjaponici Platonova, 1971 & $0,7 \pm 0,2$ & $3,8 \pm 1,7$ & $25,5 \pm 6,3$ \\
\hline Polygastrophora $\mathrm{sp}$. & $1,0 \pm 0,4$ & - & - \\
\hline Sabatieria pulchra Schneider, 1906 & $0,5 \pm 0,2$ & - & - \\
\hline Siphonolaimus sp. & $0,2 \pm 0,1$ & - & - \\
\hline Sphaerolaimus gracilis de Man, 1876 & $3,7 \pm 0,5$ & $0,7 \pm 0,2$ & $0,5 \pm 0,2$ \\
\hline Sphaerolaimus limosus Fadeeva, 1983 & - & $0,2 \pm 0,1$ & - \\
\hline Steineriacopiosa Fadeeva, 1991 & $0,5 \pm 0,2$ & - & - \\
\hline Terschellingia longicaudata de Man, 1907 & $2,7 \pm 0,6$ & - & $0,5 \pm 0,2$ \\
\hline Theristus brevisetosus Alekseev, 1992 & - & - & $5,0 \pm 0,7$ \\
\hline Tripyloides sp. & $2 \pm 0,5$ & $0,5 \pm 0,2$ & $9 \pm 3,2$ \\
\hline Всего нематод: & $80,45 \pm 19,8$ & $55,49 \pm 14,48$ & $88,0 \pm 26,48$ \\
\hline \multicolumn{4}{|l|}{ Copepoda } \\
\hline \multicolumn{4}{|l|}{ Cyclopoida } \\
\hline Eucyclops sp. copepodit & $0,5 \pm 0,3$ & - & - \\
\hline \multicolumn{4}{|l|}{ Harpacticoida } \\
\hline Halectinosoma sp. & - & - & $1,0 \pm 0,6$ \\
\hline Huntemannia biarticulatus Shen, Tai, 1973 & $1 \pm 0,7$ & - & - \\
\hline Onychocamptus mohammed Blanchard, Richard, 1891 & & $1,5 \pm 0,4$ & $0,5 \pm 0,3$ \\
\hline Remanea naksanensis Back, Lee, Huys, 2011 & - & - & $0,5 \pm 0,3$ \\
\hline Scutellidium sp. copepodit & - & - & $1 \pm 0,6$ \\
\hline Всего гарпактикоид: & $1,5 \pm 0,3$ & $1,5 \pm 0,3$ & $3 \pm 0,5$ \\
\hline
\end{tabular}




\section{Список литературы:}

1. Wilson J.G., Fleeger J.W. Estuarine benthos // Estuarine Ecology. Second Edition. Edited by John W. Day Jr. et. al. Hoboken, NewJersey: JohnWiley\&Sons. 2013. P. 303-324.

2. Heip C., Vincx M., Vranken G. The ecology of marine nematodes // Oceanogr. Mar. Biol. Ann. Rev. 1985. Vol. 23. P. 399-489.

3. Fonseca G., Netto S. Macroecological Patterns of Estuarine Nematodes // Estuaries and Coasts. 2015. Vol. 38. P. 612-619.

4. Михайлик Т.А., Тищенко П.Я., Колтунов А.М., Тищенко П.П., Швецова М.Г. Влияние реки Раздольной на экологическое состояние вод Амурского залива (Японское море) // Водные ресурсы. 2011. Т. 38, № 4. C. 474-484.

5. Warwick R.M., Gee J.M. Community structure of estuarine meiobenthos // Mar. Ecol. Prog. Ser. 1984. № 18. P. 97-111.

6. Austen M.C., Warwick R.M. Comparison of univariate and multivariate aspects of estuarine meiobenthic community structure // Estuarine. Coast. And Shelf. Sci. 1989. Vol. 29. № 1. P. 23-42.

7. Удалов А.А., Мокиевский В.О., Чертопруд Е.С. Влияние градиента солености на распределение мейобентоса в эстуарии реки Черная (Белое море) // Океанология. Т. 45, № 5. 2005. С. 719-727.

8. Шорников Е.И., Зенина М.А. Остракоды как индикаторы состояния и динамики водных экосистем (на примере залива Петра Великого Японского моря). Владивосток: Дальнаука. 2014. 334 с.

9. Фадеева Н.П. Мейобентос северной части Амурского залива Японского моря // Экологические проблемы использования прибрежных морских акваторий: материалы междунар. практ. конф. Владивосток: Изд-во Дальневост. ун-та. 2006. С. 193-199.

10. Павлюк О.Н., Требухова Ю.А., Белогурова Л.С. Влияние реки Раздольной на структуру сообщества морских свободноживущих нематод Амурского залива (Японское море) // Биология моря. 2007. Т. 33, № 4. C. 253-261.

11. Важова А.С., Зуенко Ю.И. Особенности распределения биогенных элементов вдоль градиента солености в эстуариях рек Суходол и Раздольная (залив Петра Великого. Японское море) // Изв. ТИНРО. 2015. T. 180. C. 226-235.

12. Warwick R.M., Price R. Ecological and metabolic studies on free-living nematodes from an estuarine mud-flat // Estuar. cstl mar. Sci. 1979. Vol. 9. P. $257-$ 271.

13. Clarke K.R., Warwick R.M. A further biodiversity index applicable to species lists: variation in taxonomic distinctness // Marine ecology Progress series. 2001. Vol. 216. P. 265-278.

14. Smol N., Willems K.A., Govaere J.C.R., Sandee A.J.J. Composition, distribution and biomass of meiobenthos in the Oosterschelde estuary (SW Netherlands) // Hydribiologia. 1994. № 282/283. P. 197-217.

15. Soetaert K., Vincx M., Wittoeck J., Tulkens M. Meiobenthic distribution and nematode community structure in fife European estuaries // Hydrobiologia. 1995. Vol. 311, № 3. P. 185-206.
16. Удалов А.А., Мокиевский В.О., Чертопруд Е.С. Влияние градиента солености на распределение мейобентоса в эстуарии реки Черная (Белое море) // Океанология. Т. 45, № 5. 2005. С. 719-727.

17. Мордухович В.В., Фадеева Н.П. Пространственное распределение свободноживущих нематод в эстуарии реки Амур // Состояние морских экосистем, находящихся под влиянием стока реки Амур. Владивосток: Дальнаука, 2009. С. 175-193.

18. Adão H., Alves A.S., Patrício J., Neto J.M., Costa M.J.,Marques J.C. Spatial distribution of subtidal Nematoda communities along the salinity gradient in southern European estuaries // Acta oecologica. Vol. 35. 2009. P. 287-300.

19. Hua E., Zhang Z., Zhang Y. Abundance and biomass of meiobenthos in the Changjiang (Yangtze River) estuary and its adjacent waters // ActaEcologicaSinica. 2005. Vol. 25. № 9. P. 2234-2242.

20. Quang N.X., Vanreusel A., Smol N., Nguyen N.C. Meiobenthos assemblages in the Mekong estuarine system with special focus on free-living marine nematodes // Ocean Science Journal. Vol. 45, Is. 4. 2010. P. 213224.

21. Tietjen J.H. The ecology of shallow water meiofauna in two New England estuaries // Oecologia. 1969. T. 2, № 3. P. 251-291.

22. Coull C.B. Role of meiofauna in estuarine softbottom habitats // Australian Journal of Ecology. 1999. № 24. P. 327-343.

23. Nicholas W.L., Bird A.F., Beech T.A., Stewart A.C. The nematode fauna of the Murray River estuary, South Australia; the effects of the barrages across its mouth // Hydrobiology. 1992. Vol. 234. P. 87-102.

24. Фадеева Н.П., Мордухович В.В. Морские беспозвоночные Японского моря. Ч. І. Свободноживущие нематоды. Свидетельство о государственной регистрации базы данных № 2012620231, зарегистрировано в Реестре баз данных 24 февраля 2012 г. Remane A. Die Brackwasserfauna // ZoologischerAnzeiger (Jena). Suppl. 1934. Bd. 7. P. 34-74.

25. Remane A. Die Brackwasserfauna // ZoologischerAnzeiger (Jena). Suppl. 1934. Bd. 7. P. 34-74.

26. Хлебович В.В. Критическая соленость биологических процессов. Л.: Наука. 1974. 235 с.

27. Chertoprud E.S., Frenkel S.E., Kim K., Lee W. Harpacticoida (Copepoda) of the northern East Sea (the Sea of Japan) and the southern Sea of Okhotsk: diversity, taxocenes, and biogeographical aspects // Journal of Natural History. 2015. T. 49, № 45-48. P. 2869-2890.

28. Damme D., Heip C., Willems K.A. Influence of pollution on the harpacticoid copepods of two North Sea estuaries // Hydrobiologia. Vol. 112. № 2. 1984. 143 p.

Исследования разнообразия нематод выполнены при финансовой поддержке Российского фонда фундаментальных исследований (проект № 15-2902736), исследования эстуарных градиентов распределения мейобентоса выполнено за счет средств гранта РНФ соглашение № 14-50-00034. Исследования разнообразия и распределения гарпактикоидных копепод выполнены при поддержке гранта РНФ № 14-50-00029 «Научные основы создания национального банка-депозитария живых систем». 


\section{SALINITY GRADIENT MEIOBENTHOS DISTRIBUTION ON THE RAZDOLNAYA RIVER'S ESTUARY}

(C) 2018

Milovankina Alexandra Alexandrovna, postgraduate student of Ecology Department

Fadeeva Natalia Petrovna, doctor of biological sciences, professor of Ecology Department

Far Eastern Federal University (Vladivostok, Russian Federation)

Chertoprud Elena Sergeevna, candidate of biological sciences,

leading researcher of Hydrobiology Department; leading engineer of Synecology Laboratory

Lomonosov Moscow State University (Moscow, Russian Federation);

A.N. Severtsov Institute of Ecology and Evolution (Moscow, Russian Federation)

Abstract. The paper studies salinity gradient meiobenthos distribution based on the results of the benthic surveys of the Razdolnaya estuary (the Sea of Japan, Amursky Bay). The density was increased with salinity growth on the Razdolnaya River's estuary. Meiobenthos was comprised by 8 taxonomic groups (Nematoda, Copepoda, Ostracoda, Oligochaeta, Mollusca, Amphipoda, Polychaeta и Chironomidae) with the dominance of nematodes. Most of meiobenthic species are presented by marine euryhaline species and registered throughout the Razdolnaya River's estuary. Fresh water species Dorylaimus chassanicus, Hofmaenneria gratiosa, Theristus brevisetosus and nematodes of the genera Paradontophora, widespread on estuaries of Far East of Russia, were dominated in meiobenthos in oligohaline zone of estuary; Monhystrella sp. Oncholaimium japonicum, Anoplostoma cuticularia, Daptonema inversum and Harpacticoid Copepods Remanea naksanensis, Onychocamptus mohammed, Huntemannia biarticulatus, Halectinosoma sp. were dominated in mesohaline zone. Nematode community are changed by zones throughout the estuary: Paradontophora genera are dominated in freshwater and olihaline zones, as well as freshwater species (Dorylaimus chassanicus, Hofmaenneria gratiosa. Theristus brevisetosus) were presented; Monhystrella sp. are dominated and freshwater spicies are decreased in the number at the mesohaline zone; Paracanthonchus macrodon, Oncholaimium paraolium, Sabatieria finitima, Dorylaimopsis peculiaris and S. palmaris are dominated at the euhaline zone. The nematocenes of inner part of estuarine zone aren't characterized by specific species assemblage and consist of species typical for nematode community of shallow water and of marine zones.

Keywords: meiobenthos; free-living nematodes; nematocenes; harpacticoid copepods; taxonomic composition; biodiversity; estuary; salinity gradient; oligohaline zone; mesohaline zone; fresh water zone; everyhaline; species of fresh water genesis; species of marine genesis; density; biomass; distribution; Razdolnaya River; Sea of Japan.

\section{ИНТЕГРАЛЬНАЯ ОЦЕНКА ПЕРСПЕКТИВНОСТИ ИНТРОДУКЦИИ ПРЕДСТАВИТЕЛЕЙ РОДА DEUTZIA THUNВ. В ЮЖНО-УРАЛЬСКОМ БОТАНИЧЕСКОМ САДУ-ИНСТИТУТЕ УФИЦ РАН (Г. УФА)} (C) 2018

Мурзабулатова Фануза Кавиевна, младший научный сотрудник лаборатории дендрологии, лесной селекции и интродукции древесных растений

Южно-Уральский ботанический сад-институт Уфимского федерального исследовательского иентра РАН (2. Уфа, Российская Федераиия)

Шигапов Зиннур Хайдарович, доктор биологических наук, временно исполняющий обязанности председателя

Уфимский федеральный исследовательский центр РАН (2. Уфа, Российская Федераџия)

Аннотация. В работе представлены результаты интродукционного изучения видов, гибридов и сортов рода Deutzia Thunb. коллекции Южно-Уральского ботанического сада-института (г. Уфа). Коллекция дейций является одной из наиболее крупных среди декоративных кустарников в ботаническом саду. Объектами исследований являлись 12 видов и 10 сортов дейций. Интродукционные исследования всех таксонов проводились в течение 10 лет (2007-2017 гг.). На протяжении всего периода наблюдений ежегодно оценивались следующие показатели: одревеснение побегов, зимостойкость, сохранение формы роста, побегообразовательная способность, прирост в высоту, генеративное развитие, возможные способы размножения в культуре. Анализ полученных данных показывает, что видовые таксоны отнесены к трем группам: вполне перспективные, перспективные и менее перспективные.

Максимально возможными показателями характеризуются 3 вида - D. amurensis, D. glabrata, D. parviflora. Все они могут быть рекомендованы для широкого применения в озеленении населенных пунктов Республики Башкортостан. В группе перспективных и менее перспективных оказались по 4 вида. Гибриды и сорта в коллекции относятся к трем группам: перспективные (II), менее перспективные (III), абсолютно непригодные (VI); в последней группе оказался один гибрид.

Ключевые слова: Deutzia; интродукция; устойчивость; перспективность интродукции; таксон; род; представитель; цветение; ассортимент; выбор; условия; интегральная оценка; выносливость; коллекционный фонд; фактор; шкала; декоративное садоводство; растение; показатель; степень; побег. 